\title{
Research about Rainwater Collection and Utilization in Urban Scenic Areas--Taking the scenic area construction of Nanchang Wanshou Tower as the example
}

\author{
Shuzhen Zou*a , Chaojun Wei, Biaohong Tao, Ming Zhu \\ Jiangxi Science \& Technology Normal University, Jiangxi, Nanchang, China \\ assz2928@qq.com
}

Keywords: Rainwater landscape design; Nanchang; Wanshou Tower

\begin{abstract}
Taking the scenic area of Nanchang Wanshou Tower as the example, this study applies rain flood management into the landscape design of the targeted lake wetland park and carries out a comprehensive analysis about the combination condition of rainwater collection management and different types of landscape design including park road surface, green land, pond, roof garden, road, parking lot and so on, thereby hoping to provide reference and enlightenment for the rainwater utilization in Jiangxi and the development, design and study of scenic spot ecology.
\end{abstract}

\section{Introduction}

Under the contradictory background of current increasingly-strained water resource and continuously growing water consumption brought by the urbanization acceleration, the combination of rainwater recycling system and landscape design, which has the function of environmental protection and cyclic resource utilization, gets more and more attention. Many countries in the world have put forward many representative rainwater utilization schemes and measures, for instance, American Best Management Practices, Low Impact Development, and these applications have created many successful cases, which can provide precious experience and lessons for Chinese cities still in development. Learning advanced theories and experience, combining with local actual conditions and establishing characteristic rainwater ecology landscape design in Nanchang is a problem the urban constructors must face.

\section{Overview}

\subsection{Geographical location}

Wanshou Tower scenic area is located in Nanchang Elephant Lake, which is one of eight lakes in Nanchang, located in the southwest corner of the urban area and named due to its elephant-shaped water surface. It is adjacent to Mei Lake in the south, Fu River northward and Yudai River eastward, and connects many rivers including Fu River, Yudai River, Qingshan Lake, Mei Lake, Gan River ${ }^{[1]}$, covering a total area of about 10 square kilometers and a water area of 4.55 square kilometers.

\subsection{Park environment}

Wanshou Tower scenic area is comprised of Wanshou Tower, Yijing Park, Wanshou Tower Park, Front Park Square, Water-adjacent Square in east park district, west park entrance and buildings. It covers a land area of 1.0287 million square meters, in which the greening area occupies 0.6904 million square meters, plaza area 22.8 thousand square meters, road area 100.2 thousand square meters, building area 16.3 thousand square meters, also including 1 dock and 9 bridges. Wanshou

\footnotetext{
* Shuzhen Zou , Professor of Jiangxi Science \& Technology Normal University, main research direction: environmental art; Chaojun Wei,Lecturer of Jiangxi Science \& Technology Normal University, main research direction: environmental art; Biaohong Tao, Professor of Jiangxi Science \& Technology Normal University, main research direction: applied economics;Ming Zhu, Student of Jiangxi Science \& Technology Normal University, main research direction: environmental art;
} 
Tower is located at the 15-meter-high Miaoji Mountain, having a tower body with a net height of 36 meters and named after 9999 different shaped Chinese words "Shou” inside it.

\section{Principles of rainwater landscape design}

\subsection{Rainwater management principles}

The main principle of rainwater management is to improve its retention and permeation and enhance its storage and purification. A natural rainwater cycle generally include natural evaporation, plant retention, ground surface sinking, depression filling. While, large areas of ground hardening brought by urbanization transformation intercept rainwater sinking routes, creating large amounts of ground runoffs, brushing vegetation and consequently bringing much environmental pollution. Therefore, in landscape design, what's to be done firstly is to restore ground sinking routs, enlarging ground sinking coefficient so as to make rainwater return and replenish ground and underground water naturally.

The detained rainwater may have pollutants from air, waste water, soil and so on. Therefore, it still needs absorption and purification by plants and soil to reach recycling standards. The best environment-friendly rainwater purification measures include biological retention bond, roof garden, rainwater garden and rainwater wetland.

\subsection{Landscape design principles}

Rainwater landscape design follows the following three principles: the first one is to respect primitive environment, aboriginal culture and modern technology, which is mainly embodied in keeping primitive geographic features as much as possible, including rivers, roads, primitive animals and plants; the second is to refine the elements of local culture and apply them into landscape design's modelling, color, material and other aspects; the third is to pay attention to the application of new bio-technologies and new environment-friendly material, and combine it with landscape design and construction so as to improve scientific level and endurance.

\section{Analysis about rainwater landscape classification}

\subsection{Rainwater garden and wetland}

The district of Elephant Park takes the function of storing water and flood discharge for the south part of Nanchang city, that's why there are a lot of ponds and fishponds in the Wanshou Tower Park. The landscape construction makes full use of its original water function, the established park preserves the primitive geographical feature of dense ponds and water areas, selectively reclaims land and makes islands using lake mud according to the planning and design, and carries out ecology-keeping treatment toward original revetment. Meanwhile, based on space matching in different height and seasonal matching, large amount of countryside plants are planted in order to build a safe environment for water birds, frogs, insects, and promote its construction of the biological diversified system ${ }^{[3]}$.

1) Revetment treatment

Originally, there are star-studded and different-sized fishponds and ravines in the area. They are not connected each other. The fishponds mostly adopt artificially hardened revetments, rammed original soil or stacked stones, which changes primitive loose soil structure, damages the sinking coefficient. Rainwater can't sink normally and generally goes into fishponds directly along the runoffs, which is easy to cause flood disasters. According to the requirements of "sponge city", the renovated water ponds cancel rigid artificial cement revetments, its entry gradient is reduced to a degree less than 15, and large areas of marsh is left near pond edges for transition. The soil structure is stacked by loose pond mud, accompanied by a lot of wetland and ground cover plants, thereby forming a sunken rainwater garden and wetland size of 5 square kilometers. All the river areas are connected through water channels while keeping large amount of spacious water area. When flood 
coming, they can divide the flow to discharge the flood.

The design of various wetland communities utilize marshes and plants to enclose them, thereby consciously reducing tourists' accessible space. In this way, it can avoid the direct and indirect interference to the ecological circle brought by human activities and protect its natural cyclic status.

2) Plant selection

As for the selection of plants for rainwater garden and wetlands, the prerequisite is to respect the originality of countryside plants ${ }^{[4]}$. Through proper natural space distribution and seasonal matching, a close-to-nature multi-layer ecologically-cyclic floral is formed to provide people a feeling of going back to the nature.

In the upper air are tall arbors, which can utilize their wide and dense leaves to slow down rainfall preliminarily. In detail, cinnamomum camphora, S.matsudana, Metasequoia glyptostroboides and other water tolerant plants are selectively planted; in the middle space are shrubs including Arundo donax, Iristectorum, Rhododendron pulchrum Sweet, Lagerstroemia indica, Syzygium jambos, Prunus; emergent aquatic plants and leaf-floating plants are massively planted in the bottom marsh area, including Phragmites australis, Nelumbo nucifera, Acorus calamus Linn, Typha Linn, Lagerstroemia indica L, lythrum salicaria, Scirpus tabernaemontani, Canna indica, Nymphaea lotus L.white lotus, Cyperus alternifolius, Nuphar pumilum and Brasenia schreberi Gmelwatershield. Via different spaced plantation, the natural transition from revetment to water surface is realized. Large areas of marsh can increase the contact between rainwater and plants, thereby realizing the function of retaining and absorbing heavy metal and pathogen. After renovation, the wetland plant varieties exceed 300, which remarkably enriches the diversity and ornamental level of park plants.

Flowing through this comprehensive plant retention and purification system, the pollutant brought by air in rainwater is effectively absorbed, decomposed and settled, consequently the water quality of Elephant Lake is improved from bad-five grade before renovation to good-three. The precipitation meeting water standards is then stored in ground ponds or underground and become reserved water source for drinkable water of Nanchang. The improvement of water quality brings the prosperity of underwater biological circle. Meanwhile, fish and shrimps are cultivated, a lot of migrant birds are attracted to perch in here, which further improves water biological chain and forms a harmonious development environment of human and nature.

3) Artificial landscape

Natural renovation will finally involve human beings to form a harmonious interactive loop. The artificial landscape in wetland garden scenic spot mainly includes bridges and roads. In order to comply with the requirements of low-impact development mode as much as possible, the roads connecting big and small wetlands and ponds abandon common hardened pavements, instead, they adopt anti-corrosion hydrophilic plank roads, which are suspended one meter above wetlands using pillars, windingly connect the whole scenic spot with a length of 4.3 kilometers. Tourists can ramble on the plank pavements, contact and observe closely all sorts of aquatic animals and plants, listen to bird chirps and frog sounds. Every a hundred meters on them are different shaped corridors and resting booths designed for tourists' resting and lingering.

Distinctive bird-observing towers are also set up in the scenic spot, which adopt steel frame plus wooden wide grill appearance. In this way, they can make full use of natural sunshine and ventilation while avoiding direct sunlight. They wholly integrate with the ambient environment. At normal times, they can used for bird-viewing, when it has rain or snow, they function as resting points for tourists or birds.

\subsection{Roof garden}

In the water-adjacent Square of east park district of Wanshou Tower is a 1,000 square meter sized roof garden named "Roof Garden of Elephant Lake Tourist Service Center", which boasts of the biggest "roof garden" in the whole province. The whole project is distinctively featured and comparable to the Portland roof garden in Oregon of US. 
The garden extends straightly from the rear ground of the building to the whole building roof, its facade view is the door front of the tourist service center, while looked from its side and back, it is a garden on the slope. The whole garden is divided into several different functional areas from top to bottom, which are enclosed by small pavement and plants, covering and reflecting each other so that it can't be seen by only one glance, being attractive for tourist exploration.

On the top is a relatively spacious flat, the hunching turf surrounds colored plastic ground, at the external building edges are stone-stacking rainwater collection ditches, cobbles are laid on bottom grills. The roots of aquatic plants planted on both sides can absorb gravels and sand soil, thereby preventing soil being brushed away by the runoffs. Rainwater is rapidly collected by the rain collection ditches and combined together, then flow to under layer sloping fields along the terrain. The sloping fields are designed to be several platforms with different heights, looking like traditional terrace planted with a floral exquisitely comprised of arbors, shrubs. Grass ditches are arranged at the platform rims to collect rain, only a platform is filled with water, the water then can fall down to the next platform. Due to the retention effect of these platforms, the down flowing speed of rainwater can be effectively reduced and there is enough time for floral roots and soil to absorb and filter respectively. Every platform can be deemed as a sedimentary pool. The pollutant and noxious heavy metal brought by rainwater from air undergo multiple degradation and filtering, the purified precipitation is finally led to big water storing and filtering pool at the bottom of the building for storage. When water resource is short, it is pumped to the roof to irrigate plants, in summer days, it can also be used to relieve summer heat via spraying, as well as reducing the energy consumption of air conditioners.

There is also a miniature landscape area in the east side of the roof garden, which houses many European house and windmill models scaled down at the same proportion, as well as roads and gardens shrunk similarly. Tourists can ramble, take photos and play in it.

The small pavement in the garden mostly adopt anti-corrosion wood and water-absorbing bricks. The few cement-hardened ones are also embedded with many different sized wooden poles. These measures make sure the ground sinking coefficient can meet the rain collection standard. At the same time, it also has a feeling of close and going back to the nature in visual sense. Some garden pavements adopt the pattern like stepping stones on water surface, which is comprised of old grinding plates collected from local countryside and has a sense of vicissitudes.

The whole roof garden has over 100 kinds of plants and flowers, which are exquisitely arranged according to different flower phases to make sure flower can be seen in the garden in all of the four seasons. Apart from retaining and purifying rainwater, these plants can also absorb large amount of carbon dioxide through photosynthesis, create oxygen and purify air. They can also absorb urban radiation, reduce urban noise, adjust air temperature and humidity, establish livable environment. The roof garden's water permeation and storage functions can also effectively relieve the discharging pressure of the urban draining system.

\subsection{Hillside garden and tourist footpath}

Wanshou Tower is built on Miaoji Mountain, which lies across the middle of the scenic spot from west to east. The mountain is not high in altitude, but has steep slopes. The combination of plants, from arbors, shrubs to turfs in turn along the mountain gradient, are planted from its ridges to foothills, in which shrubs occupy the biggest proportion. Camphor, osmanthus, four bamboo, casuarina, red maples and other plants surround Wanshou Tower and cover the whole hillside, which are generally densely planted. Their leaves can retain precipitation, their roots can absorb soil and mud, so water and soil loss can be prevented. Several grass ditches are arranged along the hillside, which are distributed like a circle. Combined with large areas of short Bermuda lawns planted under the hillside, they can relieve the flowing-down momentum brought by big slopes and effectively intercept and store rainwater runoffs. At the same time, the whole mountain covered with greening plants has a significant effect on air purification, dust and noise treatment.

The tourist walking and riding pavements constructed surrounding the foothill adopt permeable 
ground which bedding is permeable and has overflow discharge structure inside. When the rain volume is relatively big, it can temporarily store the cumulative water which can't sink in time into permeable gridding cloth in the basement layer, if reaching the storage limit, water can be discharged along the overflow pipes. Along the other road side, rainwater collection ditches are designed vertically, which are covered with special-made hollowed-out stone plates. Its section is lower arc shaped, which can effectively collect redundant precipitation on the hillside and roads, then lead them to adjacent wetland and ponds for further utilization.

\subsection{Permeable parking lot}

A big ecological parking lot is set up at the entrance of the east gate to meet the parking demand of tourists. Its ground uses permeable turf bricks in which there is space for grass plantation. Its opening ratio is $20 \%$ to $30 \%$, the surface runoff coefficient being 0.05 to $0.35^{[5]}$ and the sinking coefficient close to that of fully permeable areas. Turfs can also effectively remove heavy metal residuals brought by vehicles, reduce water pollution and improve greening rate.

\section{Conclusions}

Through the analysis about design concepts of rainwater management, rainwater wetland, roof garden, permeable tourist walking pavement and parking lot, this research analyzes the design concept of rainwater landscape in the wetland park of Wanshou Tower scenic spot, hereby we can infer the conclusion that the retention of the urban flood discharge area doesn't mean it will be left unused always, instead, under the guidance of scientific theories and mature governance experience from home and abroad and combined with Nanchang's local actual environment and humanistic history, it can be exquisitely designed and constructed to realize the multi-win situation for wetland protection, environment protection education, recreation and entertainment. The ecological design concept of rainwater management of Wanshou Tower scenic spot runs through the whole process of its renovation, and successfully realizes the general objective of sustainable and cyclic utilization of water resources. The renovated Wanshou Tower scenic spot is not only a tourist attraction for citizens to take relaxation and holidays, but also an important resource for rainwater protection, utilization and education. Its successful concept is bound to bring more reference and experience for domestic urban wetland development and protection.

\section{Acknowledgement}

Fund project: 2015 Jiangxi college research project about humanistic and social science

\section{References}

[1] Investigation Report about Elephant Lake Scenic Spot. https://wenku.baidu.com/view/cf53396d804d2b160b4ec0ab.html. Oct 2013: 3-4

[2] Preliminary Design Review Report about Landscape Renovation and Upgrade Project in the Area East to the West Bund of Elephant Lake Scenic Spot. http://jndsb.jxnews.com.cn/system/2013/11/28/012821131.shtml Nov 2013

[3] Park Greening and Landscape Construction Renovation Project in Elephant Lake Scenic Spot, http://ylj.nc.gov.cn/news show.aspx?id=996. Aug $3^{\text {rd }} 2015$

[4] Wang Jia, Si Si, Che Wu, Li Junqi. Selection and Design about Rainwater Garden Plants[J]. Northern Horticulture 2012(19):77-81

[5] Xia Yuanfen, Wan Yuqiu, Wang Wie. Usage Analysis about Permeable Pavement in Urban Surface Parking Lot---Taking Nanjing as the Example[J]. Environment Science and Management, 2006, 31(5):17-20. 